\title{
FATORES INIBIDORES DA CRIATIVIDADE NA EDUCAÇÃO SUPERIOR: UM OLHAR DOS DISCENTES
}

Data de submissão: $24 / 03 / 2016$

Aceite: $16 / 02 / 2017$

Hélio Trindade de Matos ${ }^{1}$ Heidy Rodriguez Ramos² Jaime Blanco Rodrigues ${ }^{3}$

\section{RESUMO}

Este artigo apresenta os fatores inibidores percebidos por alunos do curso de Administração de Empresas à promoção de condições adequadas à expressão e ao desenvolvimento da criatividade na formação profissional. Investiga os fatores inibidores à promoção da criatividade no Ensino Superior apontados pela literatura, de forma individual, mas também de forma coletiva, organizando-os em três grupos: direção da unidade de ensino superior, coordenação pedagógica e corpo docente. A pesquisa foi realizada em Instituições de Ensino Superior (IES), duas privadas e uma pública, com a participação de 262 alunos. Os resultados indicaram que os principais fatores inibidores à promoção da criatividade são os relativos à direção e ao corpo docente da IES. De forma individual, os três principais fatores inibidores apontados pelos alunos foram: escassez de recursos materiais, elevados números de alunos em sala de aula e presença de alunos indisciplinados que perturbam o trabalho docente. Destaca-se que a percepção quanto aos fatores inibidores não variou entre os alunos da instituição pública e os das instituições privadas.

Palavras-chave: Fatores inibidores. Desenvolvimento da criatividade. Ensino superior.

\footnotetext{
1 Possui graduação em Gestão de Pequenas e Médias Empresas pela Universidade Estadual Vale do Acaraú, UVA-CE, graduação em CST Gestão Empresarial pela UVA-CE, graduação em bacharelado em administração de empresas pela Universidade Federal do Maranhão, UFMA, mestrado em Desenvolvimento Socioespacial e regional pela Universidade Estadual do Maranhão, UEMA e doutorado em Administração pela Universidade Nove de Julho, UNINOVE. São Luís - MA. Brasil E-mail: heliomatos2010@gmail.com 2 Possui graduação em Administração pela Faculdade de Economia Administração e Contabilidade da Universidade de São, FEA/ USP, mestrado em Sociedade Economia e Estado pelo Programa de Pós-Graduação em Integração da América Latina, PROLAM/ USP e doutorado em Administração pela FEA/USP. São Paulo - SP. Brasil. Professora e pesquisadora no Mestrado Profissional em Administração - Gestão Ambiental e Sustentabilidade (MPA-GeAS), no Programa de Pós-graduação em Cidades Inteligentes e Sustentáveis (PPG-CIS) e no Programa de Pós-graduação em Administração (PPGA) da Universidade Nove de Julho (UNINOVE). E-mail: heidyr@gmail.com

3 Possui graduação em Engenharia Eletrônica pela Universidade Federal do Pará, UFPA, graduação em Administração pela Universidade Presbiteriana Mackenzie, MACKENZIE e mestrado em Administração de Empresas pelaMACKENZIE.

E-mail: jaimeblanco050@gmail.com
} 


\section{INTRODUÇÃO}

A capacidade de criar, inovar e diferenciar é um fator necessário ao profissional empreendedor, que deve estar sempre preparado para as exigências e mudanças do ambiente, o que impõe aos acadêmicos de administração a necessidade de desenvolvimento do seu potencial criativo. A demanda por profissionais criativos e competentes, capazes de estabelecer estratégias eficientes, identificar oportunidades, abordar e resolver problemas imprevisíveis, tem sido a ênfase das organizações, como observado por Alencar (2010) e Cropley (2005), entre outros autores. Assim, de acordo com Bilton (2007), a criatividade permite que o profissional atue sobre as oportunidades, de modo a gerar vantagem competitiva para a organização, possibilitando a base para a inovação e para o crescimento das empresas.

No âmbito do ensino superior, inúmeros trabalhos científicos evidenciam as buscas por métodos criativos, didática e práxis, objetivando responder a diversas questões, tais como: de que forma ocorre a criatividade no ensino superior; qual o papel da criatividade na práxis do docente e como produzir uma ação criativa que cause impacto em suas atividades. Nesse sentido, segundo Abreu e Masseto (1990), Pimenta e Anastasiou (2002), Anastasiou e Alves (2003), Zabalza (2004) e Barreto (2007), a efetiva transição da docência baseada no ensino para a docência baseada na criatividade e aprendizagem leva os docentes a uma dupla competência: a competência científica, como conhecedores fidedignos do âmbito científico ensinado; e a competência pedagógica, como pessoas comprometidas com a formação e a aprendizagem dos estudantes.

Dentre as diferentes questões pesquisadas sobre o tema "Criatividade no Ensino Superior", destacam-se: as habilidades de pensamento criativo dos estudantes (CHEUNG ET AL., 2003); a avaliação sobre o nível de criatividade de alunos e professores (ALENCAR, 2002); os atributos do professor facilitador e inibidor da criatividade (ALENCAR, 2000); as barreiras à criatividade pessoal (ALENCAR; MITJÁNS MARTíNEZ, 1998; ALENCAR; FLEITH; MITJÁNS MARTÍNEZ, 2003); a percepção de estudantes e professores universitários com relação à eficácia e criatividade docente (SOUZA, 2001); a percepção de estudantes e professores da educação superior sobre o ensino inovador (JASKYTE; TAYLOR; SMARIGA, 2009); a percepção de estudantes e professores referente às condições favoráveis à promoção da criatividade (ALENCAR; FLEITH, 2008b; SOUZA; ALENCAR, 2006); as expressões da criatividade, a autoavaliação sobre o nível de criatividade e as formas de estimular e desenvolver a criatividade docente e discente (PARNES, 1988; ALENCAR, 2002; CASTANHO, 2000) e a importante pesquisa sobre fatores inibidores à criatividade na educação superior (ALENCAR; FLEITH, 2010).

Quanto à realização de estudos específicos sobre as barreiras à promoção da criatividade na Educação Superior, Alencar e Fleith (2010) destacam os estudos de Jackson et al. (2006), Edwards, McGoldrick e Oliver (2006), Fryer (2006) e Alencar e Fleith (2008a), que sinalizam possíveis fatores inibidores da criatividade no ensino superior, tais como as atitudes e resistências do corpo docente e discente; elementos organizacionais de natureza estrutural, cultural e processual; tempo e outros recursos; e políticas governamentais.

Observa-se que os estudos realizados procuram entender a criatividade sob o ponto de vista do ensino e da eficácia docente, tornando necessária a realização de estudos que busquem o ponto de vista dos discentes, de forma a ser compreendido seu relacionamento com a estrutura, a prática pedagógica e o corpo docente das unidades de ensino superior.

Partindo do trabalho desenvolvido por Alencar e Fleith (2010) sobre os elementos percebidos pelos docentes da educação superior como inibidores à promoção de condições adequadas ao desenvolvimento e à expressão da criatividade dos discentes, foi estabelecida como 
problemática para este estudo a identificação dos fatores que impedem a promoção e o desenvolvimento da criatividade no ensino superior sob o ponto de vista dos alunos. Para tanto, o objetivo geral é identificar os principais empecilhos à promoção e ao desenvolvimento da criatividade no ensino superior, a partir de uma pesquisa com estudantes universitários do curso de Administração de Empresas.

Este trabalho está estruturado em quatro seções: a primeira, que consiste nesta introdução, apresenta a problemática e o objetivo da pesquisa; a segunda aborda o referencial teórico que a fundamenta; a terceira, na qual está descrita a metodologia utilizada, e, finalmente, na quarta seção, têm-se a apresentação dos resultados e as considerações finais.

\section{REFERENCIAL TEÓRICO}

\subsection{Compreendendo a criatividade}

O estudo sobre a criatividade tem alcançado progressos consideráveis desde que Milford Brad, no Graham's Magazine em 1829, considerou que, se o fornecimento de sangue ao cérebro era o fator mais importante da genialidade, o cabelo ruivo constituía uma característica observável do gênio (FRIEDEL, 1992). Posteriormente, mesmo precedido por trabalhos como os de Vasary, em 1568 (BOORSTIN, 1993), e o estudo de Sócrates por Lélut, em 1836 (PRENTKY, 1989), é ao livro de Sir Francis Galton, Hereditary Genius, de 1870, que se atribui o início do estudo da criatividade.

De acordo com Piirto (1992), sob a ótica etimológica, as palavras 'criar' e 'criatividade' estão relacionadas ao vocábulo grego greer, que significa produzir e crescer; ao latino crescere; e a Ceres, deusa romana que Ihe dá o significado de crescer da terra, ou ainda, partir do inerte. Para ele, o significado de 'criatividade' pode ser construído a partir da soma de alguns elementos, tais como: curiosidade, capacidade de visão das coisas sob um ângulo inusitado, perseverança, autoconfiança, humildade para perceber os próprios limites e percepção da utilidade de uma ideia.

Para Galton (1979) a excelência em diversos domínios possuía um conjunto comum de causas, tais como a capacidade inata, a vontade de trabalhar e um poder para realizar uma atividade muito exigente, referindo-se à inteligência. Já para Amabile (2001), esta é aceita como apenas um dos componentes da criatividade; necessária, mas não suficiente para a sua efetivação. Para ela, o valor social da criatividade só se firma quando associado às formas pelas quais a sociedade reconhece a inteligência.

Runco (1995) esclarece que as diversas teorias sobre a criatividade podem ser agrupadas em dez categorias que sistematizam a sua compreensão. São elas: desenvolvimentista: a criatividade se desenvolve ao longo do tempo; psicométrica: a criatividade pode ser medida; econômica: a ideia criativa é influenciada pelas forças do mercado e pela análise de custo benefícios; estágio e processo: a expressão criativa surge através de etapas ou componentes; cognitiva: pensamentos criativos são fundamentais para a criatividade; solução de problemas e base de experiência: soluções criativas a partir de um processo racional; busca de problema: pessoas criativas agem proativamente e o processo exploratório de identificação de problemas a serem resolvidos; evolucionária ou Darwinista: evolução da criatividade semelhante ao processo Darwinista; tipológicas: criações variam como as diferenças individuais; e sistema: a criatividade resulta de uma série fatores interativos e inter-relacionados.

Portanto, a criatividade pode ser investigada por meio de diversas abordagens, sendo a mais usual a que considera os chamados 4Ps (Person, Process, Product, Press), proposta por 
Rhodes (1961). Nela, a criatividade foi considerada como um fenômeno, no qual uma pessoa comunica um novo conceito, o produto. A pessoa chega até esse produto por meio de um processo mental, pois, como nenhum ser humano vive ou opera no vácuo, é necessário considerar o ambiente (PEARSON, 2011). Enfim, como proposto por Christian De Cock (1993), referindo-se à proposição inicial de Mackinnon (1963), ao se investigar o construto criatividade, é necessário que se trate da pessoa, do processo, do produto e do ambiente criativo.

Mais recentemente, Csikszentmihályi (1990) e Gardner (1994) propuseram a divisão do estudo da criatividade, levando em conta os aspectos de campo, com indivíduos e instituições que julgam os produtos; o domínio, a estrutura e as práticas associadas a um dado campo de conhecimento; e o indivíduo. Já Sternberg e Lubart (1995) propuseram o estudo da criatividade englobando seis aspectos: capacidades intelectuais, conhecimento, estilos de pensamento, personalidade, motivação e ambiente.

Dois níveis de análise são geralmente apresentados como parte de um contínuo, entre um polo em que a criatividade pode ser vista apenas como "fazer melhor aquilo que se faz", a criatividade com " $\mathrm{c}$ "; e o polo oposto, a criatividade com " $\mathrm{C}$ ". A criatividade com " $\mathrm{c}$ " constituiria o motor de estudo dos processos destinados a desenvolvê-la nos indivíduos, e a criatividade com " $C$ " seria o construto a partir do qual toda a compreensão do fenômeno deve ser vista como complemento da primeira, podendo ser aplicada, além de individualmente, em grupos, organizações e sociedades. Portanto, considera-se que a criatividade pressupõe a comunicação ativa, sob a forma de persuasão, como afirma Simonton (1991) tanto criar como liderar são formas de comunicação.

\subsubsection{A pessoa criativa}

Uma das questões mais recorrentes nos estudos sobre a pessoa criativa, refere-se à possibilidade de a criatividade ser aprendida ou não. Para Terra (2012), a resposta não é simples e requer uma reflexão aprofundada sobre o que vem a ser a criatividade. $O$ autor destaca que não há teste fidedigno para medir quantitativamente e de forma precisa a criatividade de uma pessoa. Para ele, a criatividade se manifesta de diferentes formas, tendo como única forma de mensuração o reconhecimento de outras pessoas.

No entanto, Terra (2012) considera que é plenamente possível tornar alguém mais criativo, uma vez que a criatividade se revela a partir de associações e combinações inovadoras de planos, modelos, sentimentos, experiências, associações e fatos. Assim, torna-se fundamental propiciar oportunidades e incentivar os indivíduos a tentarem novas experiências, a testarem hipóteses e, principalmente, a estabelecerem novas formas de diálogo com pessoas de outras formações, com outros tipos de experiências e culturas.

Diante do que foi exposto, esclarece-se que vários outros autores defendem a ideia de que as pessoas se tornam criativas de acordo com o contexto em que estão inseridas, no qual assumem um papel preponderante. Conforme estudos de Ferreira e Candeias, citados por Runco (1995), todo indivíduo tem potencial para ser criativo, mas nem todos fazem uso dele por falta de oportunidades para desenvolvê-lo.

\subsubsection{O processo criativo}

Segundo Stein (1989), processo criativo é aquilo que ocorre no indivíduo, ou entre indivíduos, que também é percebido por outros, tendo em vista a construção de um produto ou 
resposta criativa. Esses processos podem ser primários de associação livre, como um sonho; ou secundários de pensamento racionais, orientados para a realidade.

O modelo mais conhecido de processo criativo ocorre em quatro fases distintas, sendo elas: a preparação, fase correspondente à coleta de informações sobre um problema; a incubação, fase que corresponde a um afastamento do problema; a iluminação, fase na qual a pessoa encontra a solução do problema; e a verificação, fase em que ajustes são feitos na solução identificada. Entretanto, com a evolução dos estudos sobre o processo criativo, alguns pesquisadores consideram que as fases de iluminação ou fenômenos de inspiração não existem (FRYER, 1996), concluindo, que as pessoas criativas desenvolvem processos de pensamento iguais aos das pessoas ditas comuns (WEISBERG, 1991).

\subsubsection{O produto criativo}

Segundo Amabile (2001), um produto ou resposta pode ser caracterizado como criativo na medida em que ele se constitui, simultaneamente, de uma novidade ou resposta útil, valorizando a realização da tarefa em curso, desde que seja uma resposta heurística e não uma sequência finita de ações a serem seguidas de forma mecânica. Dessa forma, as noções de valor e originalidade são os grandes diferenciais para o reconhecimento de um produto criativo.

As noções de originalidade e valor remetem à definição de Rothenberg (1990) sobre a criatividade. Para o autor, o produto criativo é a ação resultante da criatividade, sendo esta a capacidade ou estado que produz criações e produtos novos com valor. Chega-se à conclusão de que existe criatividade pela simples aparição de uma ideia, isto é, aquilo que é percebido mentalmente e não através dos sentidos, seja isso constituído por objetos, suas relações ou imagens mentais desses mesmos objetos. A criatividade é, portanto, um produto do pensamento na tentativa de estabelecer uma ordem no mundo percebido, sob a forma de um produto ou resposta.

Considera-se, ainda, a existência de um contraste entre a motivação intrínseca e a extrínseca na obtenção de um produto ou resposta. A motivação intrínseca atua para que o indivíduo desenvolva suas atividades com muito mais criatividade e paixão, enquanto que a extrínseca atua no meio para chegar ao resultado. Como exemplificado por Amabile (2001), o trabalho é um meio de se ganhar dinheiro, portanto o estado de motivação intrínseco conduz à criatividade na sua execução, já o extrínseco torna o trabalho cansativo, ou seja, é prejudicial à criatividade.

\subsubsection{0 ambiente criativo}

Para Alencar e Mitjáns Martínez (1998), existe uma necessidade por parte das organizações de se relacionarem com a criatividade, devido a sua importância no processo de mudança, instabilidade e concorrência, uma vez que a criatividade colabora para o desenvolvimento das inovações. Entretanto, para as autoras, muitas organizações não atentam para essa necessidade, principalmente no sentindo de minimizar possíveis barreiras encontradas nos ambientes. A atividade criativa só pode ser exercida plenamente dentro de um clima aberto e liberal, de forma independente aos constrangimentos exteriores, materiais ou morais (ALENCAR; MITJÁNS MARTÍNEZ, 1998). Sendo assim, a criatividade só pode subsistir onde o ambiente seja favorável ao processo no seu todo.

Nessas condições, as autoras destacam a necessidade de existirem nas organizações líderes criativos, que ficariam responsáveis pelo cultivo de um ambiente criativo, facilitando o surgimento de ideias criativas ao promoverem um local de apoio a ideias inovadoras. Existem 
nove fatores que tornam uma sociedade mais favorável à geração das novas ideias, sendo eles: disponibilidade de meios culturais; abertura a estímulos culturais; existência de tensão interna que leve o indivíduo a questionar o status quo; acesso livre aos meios culturais; liberdade; exposição a estímulos culturais diferentes; tolerância a diferentes visões; interação entre personalidades importantes que se confrontam e enriquecem; e a existência de incentivos e prêmios.

Considera-se, portanto, que, de acordo com Guilford (1950), a criatividade pode ser compreendida como uma habilidade universal que necessita de reconhecimento e de estímulo. Isso torna necessário o desenvolvimento de uma plataforma para que a criatividade esteja presente no ambiente das organizações, ou seja, como defendido por Alencar e Martínez (1998), para que as organizações possam reconhecer as potencialidades e ofertar condições para o desenvolvimento de ideias criativas.

\subsection{Fatores inibidores à criatividade no Ensino Superior}

Aparentemente, a relação entre a educação e a criatividade acontece de forma natural, mas, de acordo com Plucker, Beghetto e Dow (2004), em muitas situações, não parece ser isso o que acontece, principalmente diante das mudanças de paradigmas que a sociedade do conhecimento está impondo. Para Sternberg e Lubart (1995), isso provavelmente tornará imprescindível a reestruturação do sistema educacional, com a adoção de novos conceitos e práticas que preparem e qualifiquem os novos profissionais para atenderem aos desafios do mercado de trabalho, devendo ser observados alguns preceitos como a integridade e a individualidade, proporcionando aos profissionais o pleno desenvolvimento de suas potencialidades.

Hargreaves (2003) esclarece que a sociedade do conhecimento, ao apoiar-se em novas tecnologias, se encontra em evolução constante, possibilitando aos indivíduos a oportunidade de vivenciarem situações que os incentivem a ser criativos e que lhes traga como consequência a formação de uma nova identidade, que se traduzirá em níveis elevados de satisfação pessoal e eficiência produtiva. Assim, é preciso que ocorra, por parte dos responsáveis pela gestão das Instituições de Ensino Superior (IES), a redução de locais e de qualquer unidade de ensino onde o ambiente seja hostil ou, simplesmente, indiferente a novas ideias, uma vez que é pouco provável que a criatividade se desenvolva em ambientes assim.

Em conformidade com Alencar e Fleith (2010), destacam-se alguns estudos realizados com o objetivo de identificar as barreiras ao uso da criatividade no ensino superior. Sobressai-se, dentre eles, o estudo realizado por Jackson et al. (2006), que consideraram como fatores inibidores a resistência de docentes e discentes, os elementos de natureza estrutural, a cultura processual, o tempo e as políticas públicas. Outro estudo importante foi o de Edwards, McGoldrick e Oliver (2006), que, ao pesquisarem as perspectivas de docentes quanto ao uso da criatividade em sala de aula, constataram seus receios em assumir riscos devido a existência de uma cultura que não tolera o fracasso.

Ao realizar estudos sobre os fatores inibidores ao uso da criatividade no ensino superior, Fryer (1996) identificou, em sua pesquisa com noventa docentes de IES, que a presença de recursos inadequados; a carga excessiva de trabalho, o tempo inadequado de preparação das aulas, o grande número de alunos em sala de aula e o tempo insuficiente para contato com os alunos são elementos inibidores à expressão da criatividade na educação superior. Além disso, os estudos de Alencar e Fleith (2008a) sobre os fatores facilitadores e inibidores da criatividade individual, com estudantes de engenharia, também apontaram como barreira a distância entre a universidade e o mercado de trabalho. 
De acordo com Alencar (2002), existem ainda outras barreiras que são apontadas pelos docentes: a falta de habilidades na relação com os alunos, o que os impede de se expressar criativamente; não saber como adequar a sua linguagem à faixa etária para tornar mais eficiente a comunicação; não se sentirem preparados para o controle disciplinar dos alunos; e a inabilidade para preparação de aulas diversificadas e agradáveis, por receio de prejudicar o conteúdo.

Para Moreira (2007), o ambiente de aprendizagem é um lugar previamente organizado para promover oportunidades de conhecimento. Como tal, se constitui de forma única, na medida em que é um ambiente socialmente construído por alunos e professores a partir das interações que estabelecem entre si e com as demais fontes materiais e simbólicas presentes. Nesse sentido, uma outra barreira foi apontada pelas pesquisadoras Alencar e Fleith (2010), que, ao entrevistarem professores sobre facilitadores e inibidores à criatividade pessoal e sobre os elementos do ambiente e de variáveis pessoais que facilitam ou dificultam a expressão da criatividade, levantaram a hipótese de que a práxis pedagógica, ou seja, a forma como o ensino era conduzido, correspondia também a um fator inibidor à promoção da criatividade no ensino superior.

\section{METODOLOGIA}

Para o desenvolvimento deste trabalho, foi adotada a metodologia quantitativa, que, de acordo com Malhotra (2001, p. 154), corresponde "a uma metodologia que proporciona insights e compreensão do contexto do problema [...] procura quantificar os dados e aplica alguma forma da análise estatística". Assim, o pesquisador pode estabelecer o significado de um fenômeno a partir do ponto de vista dos participantes (CRESWELL, 2010).

Quanto ao seu objetivo, o estudo é caracterizado como descritivo. Esse tipo de pesquisa tem como principal objetivo descrever características de determinada população ou fenômeno ou estabelecer relações entre as variáveis (GIL, 2014). Devido a coleta de dados para a realização dessa pesquisa ter ocorrido uma única vez, esse estudo também é caracterizado como um estudo de corte transversal (HAIR ET AL., 2005).

Foram adotados como unidades de análise da pesquisa os estudantes de administração de duas Instituições Privadas de Ensino Superior (IES), situadas no Estado de São Paulo, e de uma Instituição Pública, situada no Estado do Maranhão, escolhidas por intencionalidade. Participaram do estudo os alunos do curso de Administração da Instituição Pública de São Luís do Maranhão e os das Instituições Privadas da cidade de Cotia, do estado de São Paulo. A escolha dessas cidades foi realizada pela acessibilidade dos pesquisadores à coleta dos dados. A população de alunos participantes nesta pesquisa foi de 262 alunos, sendo $141(53,8 \%)$ do gênero masculino e $121(46,2 \%)$ do gênero feminino. Desse total, 93 alunos (24,7\%) estudavam em universidade pública e 169 alunos (64,3\%) em instituição particular de educação superior. A idade dos participantes variou entre 17 e 44 anos.

Quanto ao método de coleta de dados, foi utilizado um questionário com uma lista de fatores inibidores à promoção de condições da criatividade na aprendizagem. Essa lista de fatores corresponde a uma adaptação da lista utilizada na pesquisa desenvolvida e disponibilizada pelas professoras Alencar e Fleith (2010). Explicita-se que alguns fatores inibidores presentes na lista original não foram incluídos, por não serem considerados pertinentes a este estudo. Diferentemente da pesquisa de Alencar e Fleith (2010), o questionário foi composto de modo a ser possível obter a informação agregada dos fatores inibidores em três grupos: direção da unidade de ensino superior, coordenação pedagógica e docente. 
Utilizou-se uma escala tipo Likert de 5 pontos para mensurar o grau de concordância dos estudantes que responderam ao questionário. A concordância ou discordância com os fatores avaliados foi verificada por meio da obtenção das frequências das respostas dos estudantes, em que o menor valor indicava discordância total com a assertiva apresentada e o maior valor representava total concordância. O ponto intermediário foi considerado indiferente.

Quanto aos procedimentos de coleta de dados, foi conduzido um estudo piloto com 10 alunos do curso de Administração de uma universidade pública do estado do Maranhão, de modo a garantir a clareza das instruções e identificar a possível necessidade de revisões na estrutura dos itens incluídos no questionário. A participação dos alunos ocorreu de forma voluntária e em conformidade com as exigências éticas, sendo assegurado o caráter confidencial das respostas fornecidas, uma vez que os dados foram analisados de forma coletiva. $\mathrm{O}$ questionário foi respondido de forma individual, sempre na presença de um pesquisador e mantendo as condições citadas pelo estudo original. A coleta de dados ocorreu nos meses de agosto a outubro de 2014. Para sua análise, foram calculadas a frequência e a porcentagem para cada item do questionário, apresentando o total geral, e por gênero, e o tipo de instituição de ensino superior, pública ou privada.

\section{RESULTADOS E DISCUSSÃO}

Destaca-se que, diferentemente do estudo realizado por Alencar e Fleith (2010), o presente trabalho optou pela agregação dos fatores inibidores à promoção das condições adequadas à expressão e ao desenvolvimento da criatividade em três grupo distintos, a saber: direção, coordenação pedagógica e corpo docente da instituição de ensino superior. Conforme foi descrito na metodologia, esta pesquisa foi conduzida com os discentes das instituições.

$O$ resultado agrupado desses fatores é apresentado na Tabela 1. Ele se torna importante na medida em que demonstra que os fatores inibidores, segundo a ótica dos alunos, estão distribuídos nos três grupos de forma homogênea, com uma leve acentuação na direção das instituições de ensino superior (36\%), provavelmente pela maior liberdade dos alunos para responderem questões relativas à direção da IES.

Tabela 1: Fatores inibidores à promoção de condições adequadas ao desenvolvimento e à expressão da criatividade (direção, coordenação e corpo docente)

\begin{tabular}{c|c} 
Agregados de Fatores Inibidores & Porc. \\
\hline Fatores relativos à direção da Instituição de Ensino Superior & $36 \%$ \\
\hline Fatores relativos à coordenação pedagógica da Instituição de Ensino Superior & $31 \%$ \\
\hline Fatores relativos ao corpo docente da Instituição de Ensino Superior & $33 \%$ \\
\hline
\end{tabular}

Fonte: Dados da pesquisa.

A Tabela 2, na página seguinte, apresenta a frequência e a porcentagem de respostas ao questionário de fatores inibidores à promoção da criatividade no ensino superior sob o olhar dos estudantes. As principais barreiras apontadas, dentro do conjunto de direção da escola, foram: presença de alunos indisciplinados que perturbam o trabalho docente (66\%), elevado número de alunos em sala de aula $(62,2 \%)$ e escassez de recursos materiais básicos $(61,1 \%)$. Esses resultados chamam a atenção quando comparados às respostas dos professores no estudo de Alencar e Fleith (2010), no qual esses fatores obtiveram respectivamente $21,9 \%, 40,2 \%$ e $29,0 \%$ das respostas. 
De acordo com a visão dos estudantes, um dos inibidores à promoção das condições adequadas à expressão e ao desenvolvimento da criatividade no ensino superior encontra-se nos próprios docentes. Tal situação, de acordo com $58 \%$ das respostas, ocorre devido ao baixo entusiasmo demonstrado por eles na realização de suas atividades. Entretanto, ao observar esse mesmo fator no estudo anterior, constata-se que apenas 3,3\% dos professores admitem a ocorrência dessa situação, corroborando a posição de Stein (1989), que defende não bastar apenas a crença do indivíduo em pensar que realiza processos criativos, sendo também necessário que esses processos sejam percebidos por outras pessoas.

Quanto aos resultados relativos ao grupo de coordenação pedagógica, destacou-se, na visão de $58 \%$ dos alunos, o baixo incentivo da direção pedagógica para propor outras práticas de ensino. Esse resultado também ficou acima dos obtidos por Alencar e Fleith (2010), em que esse fator recebeu somente $24 \%$ do total de respostas. Além disso, o fator preferência por métodos tradicionais de ensino por parte dos professores alcançou, no mesmo estudo, apenas 8,6\% das respostas dos professores, enquanto que os estudantes indicaram um percentual de respostas de $48,7 \%$. São situações que parecem demonstrar a necessidade de construção de um ambiente mais favorável à criatividade nas IES, como explicitado por Alencar e Mitjáns Martínez (1998) acerca da necessidade de líderes criativos e responsáveis por criar um ambiente favorável à promoção da criatividade, apoiando ideias inovadoras.

Tabela 2: Fatores inibidores à promoção de condições adequadas ao desenvolvimento

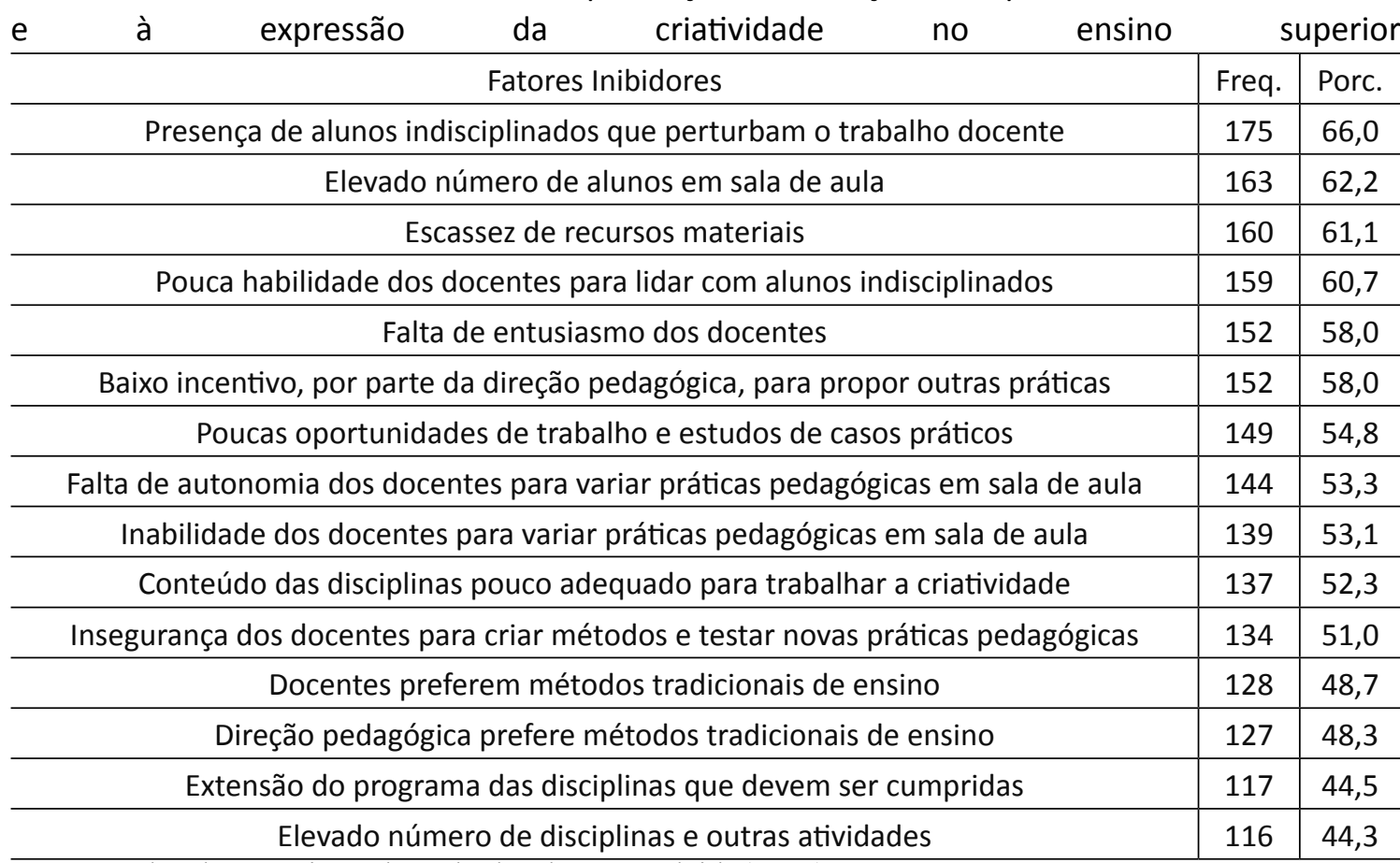

Fonte: Dados da pesquisa; adaptado de Alencar e Fleith (2010).

Na Tabela 3, são apresentadas a frequência e a porcentagem de alunos de ambos os gêneros no que se refere aos diferentes fatores inibidores. Observou-se um percentual significativamente divergente entre os alunos do gênero feminino, comparado aos do gênero masculino para os seguintes fatores inibidores, respectivamente: presença de alunos indisciplinados que perturbam o trabalho docente $(76,4 \%$ e $58,2 \%)$; baixo incentivo por parte da direção pedagógica para propor outra prática $(64,0 \%$ e $52,5 \%)$; falta de autonomia do docente para conduzir suas 
atividades (63,6\% e $46,8 \%$ ) e pouca habilidade dos docentes para lidar com alunos indisciplinados em sala de aula (67,8\% e $54,6 \%)$.

Diante do que foi exposto, as frequências das respostas aos fatores inibidores apontados evidenciam que os estudantes do gênero feminino apresentam grande preocupação com a adequação do ambiente de aprendizagem à promoção da criatividade. Isso corrobora as observações de Alencar e Fleith (2010), pois a forma como o ensino é conduzido nesse ambiente pode acabar representando um fator inibidor à promoção da criatividade. Segundo Moreira (2007), o ambiente de aprendizagem é socialmente construído pelas interações estabelecidas entre alunos, professores e demais fontes materiais e simbólicas do ambiente.

Tabela 3: Fatores inibidores à promoção de condições adequadas ao desenvolvimento à expressão da criatividade quanto aos gêneros

\begin{tabular}{|c|c|c|c|c|}
\hline Fatores Inibidores & $\begin{array}{l}\text { Mas- } \\
\text { culino } \\
\mathrm{N}=141 \\
\text { Freq }\end{array}$ & \multicolumn{3}{|c|}{$\begin{array}{l}\text { Feminino } \\
\mathrm{N}=121 \\
\text { Freq. Porc. }\end{array}$} \\
\hline Escassez de recursos materiais & 83 & 58,5 & 78 & 64,0 \\
\hline Presença de alunos indisciplinados que perturbam o trabalho docente & 82 & 58,2 & 93 & 76,4 \\
\hline Elevado número de alunos em sala de aula & 82 & 58,2 & 83 & 68,6 \\
\hline Poucas oportunidades de trabalho e estudos de casos práticos & 82 & 58,2 & 67 & 55,4 \\
\hline Falta de entusiasmo dos docentes & 79 & 56,0 & 73 & 60,3 \\
\hline Pouca habilidade dos docentes para lidar com alunos indisciplinados & 77 & 54,6 & 82 & 67,8 \\
\hline $\begin{array}{l}\text { Baixo incentivo, por parte da direção pedagógica, para propor outra práti- } \\
\text { ca }\end{array}$ & 74 & 52,5 & 78 & 64,0 \\
\hline Inabilidade dos docentes para variar práticas pedagógicas em sala de aula & 69 & 48,9 & 70 & 57,4 \\
\hline Conteúdo das disciplinas pouco adequado para trabalhar a criatividade & 68 & 48,2 & 69 & 56,6 \\
\hline Falta de autonomia dos docentes para variar práticas pedagógicas & 66 & 46,8 & 77 & 63,6 \\
\hline $\begin{array}{c}\text { Insegurança dos docentes para criar métodos e testar novas práticas pe- } \\
\text { dagógicas }\end{array}$ & 63 & 44,7 & 70 & 57,9 \\
\hline Docentes preferem métodos tradicionais de ensino & 62 & 44,0 & 65 & 53,7 \\
\hline Direção pedagógica prefere métodos tradicionais de ensino & 60 & 42,6 & 67 & 55,0 \\
\hline Elevado número de alunos em sala de aula & 58 & 41,1 & 58 & 47,9 \\
\hline Extensão do programa das disciplinas que devem ser cumpridas & 57 & 40,4 & 59 & 48,8 \\
\hline
\end{tabular}

Fonte: Dados da pesquisa; adaptado de Alencar e Fleith (2010).

Na Tabela 4, são apresentadas as barreiras indicadas pelos estudantes, comparando as instituições de ensino superior pesquisadas (a pública e as privadas). Contrariamente aos resultados identificados no estudo desenvolvido por Alencar e Fleith (2010), não foram observadas diferenças significativas entre ambos os tipos de instituição no que se refere aos fatores inibidores. Os três principais fatores inibidores apontados pelos alunos foram: escassez de recurso materiais, elevado número de alunos em sala de aula e presença de alunos indisciplinados que perturbam o trabalho docente.

Tabela 4: Fatores inibidore à promoção de condições adequadas ao desenvolvimento e à expressão da criatividade na visão de alunos das IES pública e privada 


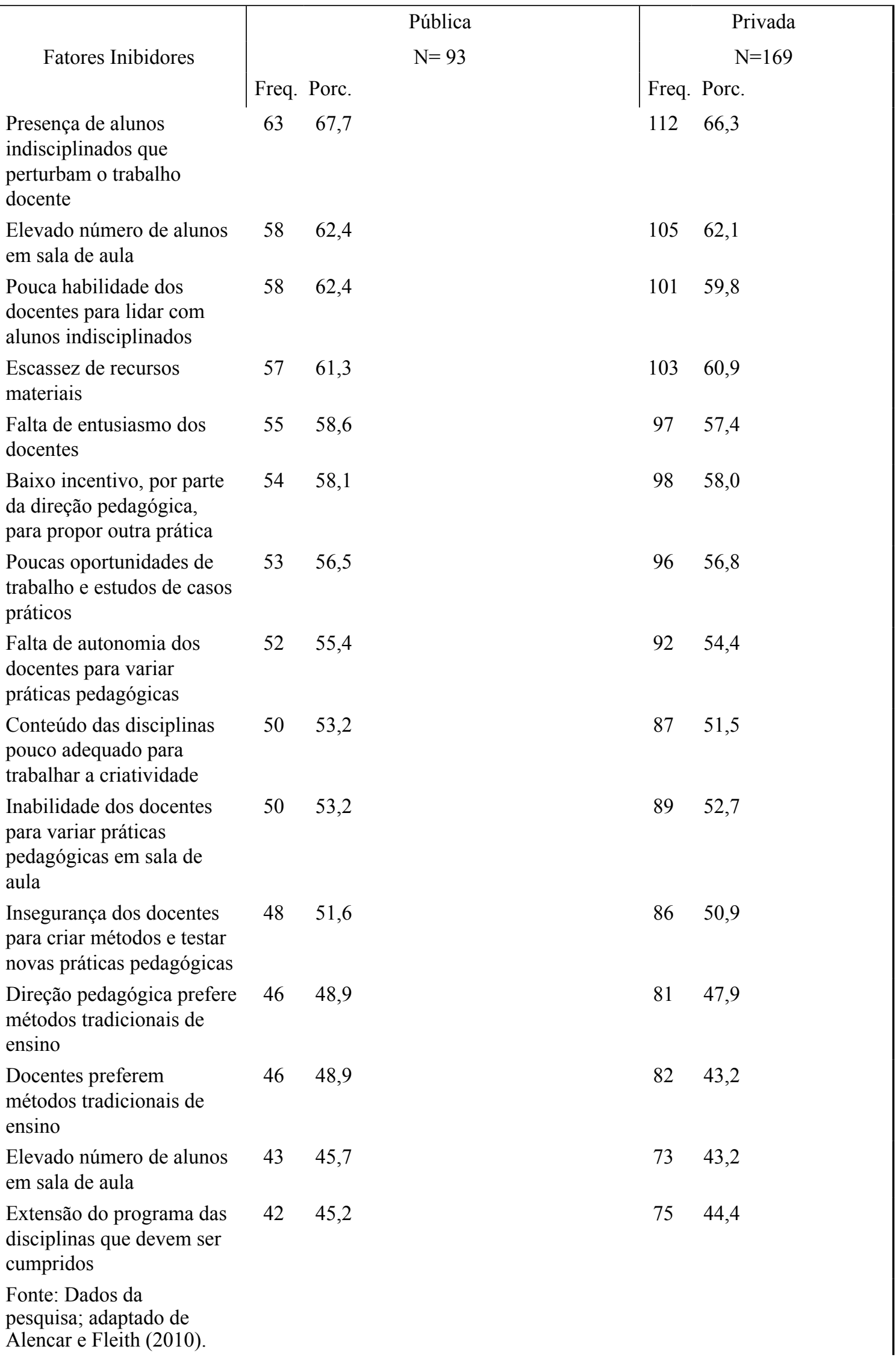




\section{CONSIDERAÇÕES FINAIS}

Os dados relativos aos fatores inibidores foram agregados em três grupos: direção da instituição de ensino superior, coordenação pedagógica e docente. Os estudantes dos cursos de Administração de Empresas consideram esses grupos, de certa forma, equivalentes no sentido de serem obstáculos à promoção da criatividade. Ocorreu apenas uma leve preponderância do fator inibidor agregado à direção da instituição de ensino superior.

Contrariamente ao que foi observado na pesquisa de Alencar e Fleith (2010), em que, das quatro maiores barreiras apontadas pelos docentes, três referiam-se ao aluno, constatou-se aqui que, ao pesquisar o olhar dos discentes, dentre os quatro fatores inibidores apontados por eles, três referiam-se à instituição de ensino superior. São eles: o elevado número de alunos em sala de aula, a escassez de recursos materiais básicos, a presença de alunos indisciplinados que perturbam o trabalho docente e, por fim, a falta de entusiasmo por parte do professor.

Destaca-se que o fator relativo ao grande número de alunos em sala foi apontado tanto pelos estudantes participantes desse estudo, bem como pelos professores na pesquisa de Alencar e Fleith (2010). Esse fator é talvez um dentre tantos outros que vão ao encontro direto do impedimento do desenvolvimento da criatividade no ensino superior. Isso acontece uma vez que um elevado número de alunos em sala de aula dificulta a adoção de novas práticas de ensino pelo docente, favorecendo, assim, a manutenção de práticas tradicionais ou funcionando como um redutor do entusiasmo dos professores.

Em relação aos resultados obtidos em pesquisas anteriores, acerca da visão dos docentes sobre os fatores inibidores à promoção e à expressão da criatividade no ensino superior, outra divergência identificada foi o equilíbrio existente na ocorrência dos fatores inibidores apontados tanto por estudantes da instituição de ensino superior pública quanto das instituições privadas.

Os resultados desse estudo apontam a necessidade de as instituições de ensino superior promoverem a existência de um ambiente de aprendizagem mais favorável à expressão da criatividade, considerando os três grupos agregados, ao estabelecerem condições para que a criatividade possa fazer parte do dia a dia da instituição, como apresentado por Alencar e Mitjáns Martínez (1998). Assim, a docência baseada no ensino tradicional - na qual o professor é o detentor e transmissor de conhecimentos e o aluno um ser passivo que apenas memoriza - cede lugar para uma docência baseada na criatividade e na aprendizagem, em que professores e alunos criam possibilidades para a assimilação do conhecimento, visando ao desenvolvimento de habilidades e competências, como preconizado por Abreu e Masseto (1990), Pimenta e Anastasiou (2002), Anastasiou e Alves (2003), Zabalza (2004) e Barreto (2007).

As análises apresentadas neste estudo buscam contribuir para a ampliação do conhecimento sobre a ocorrência da criatividade no ensino superior e, especialmente, sobre as condições de desenvolvimento da criatividade nos cursos de Administração de Empresas. Considera-se como limitação do estudo a participação de apenas três instituições de ensino superior. Propõese, como sugestão de pesquisas futuras, a realização de um estudo quantitativo com maior amplitude, com a mesma temática adotada para a realização deste trabalho. Outra sugestão é a realização de estudos acerca da utilização das tecnologias de informação e comunicação pelos estudantes universitários, considerando os diferentes fatores inibidores, apresentados neste e em outros estudos, da promoção e da expressão da criatividade no ensino superior. 


\section{REFERÊNCIAS}

ABREU, M.; MASETTO, M. O professor em sala de aula: prática e princípios teóricos. São Paulo: MG Associados, 1990.

ALENCAR, E. O estímulo à criatividade em programas de pós-graduação segundo seus estudantes. Psicologia: Reflexão e Crítica, Porto Alegre, v. 15, n. 1, p. 63-70, 2002.

ALENCAR, E. O perfil do professor facilitador e inibidor da criatividade segundo estudantes de pós-graduação. Boletim da Academia Paulista de Psicologia, São Paulo, v. 19, n. 1, p. 84-94, jan./ mar. 2000.

ALENCAR, E. Obstacles to personal creativity among university students. Gifted Education International, v. 15, n. 2, p. 133-140, 2001.

ALENCAR, E.; MITJÁNS MARTíNEZ, A. Barreiras à expressão da criatividade entre profissionais brasileiros, cubanos e portugueses. Psicologia Escolar e Educacional, Campinas, v. 2, n. 1, p. 2332, 1998.

ALENCAR, E.; FLEITH, D. Criatividade pessoal: fatores facilitadores e inibidores segundo estudantes de Engenharia. Magis, Bogotá, v. 1, n. 1, p. 113-126, jul./dic. 2008 a.

ALENCAR, E.; FLEITH, D. Barreiras à promoção da criatividade no ensino fundamental. Psicologia: Teoria e Pesquisa, Brasília, v. 24, n. 1, p. 59-66, jan./mar. 2008b.

ALENCAR, E.; FLEITH, D. Escala de práticas docentes para a criatividade na educação superior. Avaliaçao psicológica, v. 9, n. 1, p. 13-24, 2010.

ALENCAR, E.; FLEITH, D.; MITJÁNS MARTíNEZ, A. Obstacles to personal creativity between Brazilian and Mexican university students: a comparative study. The Journal of Creative Behavior, Buffalo, v. 37, n. 3, p. 179-192, third quarter 2003.

AMABILE, T. Beyond talent. John Irving and the passionate craft of creativity. American Psychologist, Washington, DC, v. 56, n. 4, p. 333-336, apr. 2001. 
ANASTASIOU, L.; ALVES L. Processos de linguagem na Universidade: pressupostos para as estratégias de trabalho em aula. Joinville, SC: UNIVILLE, 2003.

BARRETO, M. O papel da criatividade no Ensino Superior. Diálogos \& Ciência, ano V, n. 12, p. 1-13, dez. 2007.

BILTON, C. Management and Creativity: From Creative Industries to Creative Management, Oxford: Blackwell Publishing, 2007.

BOORSTIN, D. J. Os criadores. Lisboa: Gradiva, 1993.

CASTANHO, M. A criatividade na sala de aula universitária. In: VEIGA, I.; CASTANHO, M. (Org.). Pedagogia universitária. A aula em foco. Campinas: Papirus, 2000. p. 75-89.

CHEUNG, C. et al. Creativity of university students: what is the impact of field and year of study? The Journal of Creative Behavior, Buffalo, v. 37, n. 1, p. 42-63, 2003.

CSIKSZENTMIHÁLYI, M. The domain of creativity. In RUNCO, M. A.; ALBERT; R. S. (Eds.). Theories of creativity. Vol. 115, p. 190-212. Thousand Oaks, CA, US: Sage Publications, Inc, 1990.

DE COCK, Christian. A Creativity Model for the Analysis of Continuous Improvement Programmes. Creativity and Innovation Management, v. 2, n. 3, p. 156-165, 1993.

CRESWELL, J. W. Projeto de pesquisa métodos qualitativo, quantitativo e misto. Porto Alegre: Ed. Artmed, 2010.

CROPLEY, A. Creativity in education \& learning. London: Routledge, 2005.

EDWARDS, M.; MCGOLDRICK, C.; OLIVER, M. Creativity and curricula in higher education: academics perspectives. In: JACKSON, N. et al. (Org.). Developing creativity in higher education. London: Routledge, 2006. p. 59-73.

FRIEDEL, R. Perspiration in perspective. In: WEBER, R.; PERKINS, D. (Ed.). Inventive minds: 
Creativity in technology. Oxford: Oxford University Press, 1992.

FRYER, M. Facilitating creativity in higher education: a brief account of National Teaching Fellows' views. In: JACKSON, N. et al. (Org.). Developing creativity in higher education. London: Routledge, 2006. p. 74-88.

FRYER, M. Creative teaching and learning. London: Paul Chapman, 1996.

GALTON, F. Hereditary genius: An inquiry into its laws and consequences. London: Julian Friedman, 1979.

GARDNER, H. The creator's patterns. In: BODEN, M. (Ed.). Dimensions of creativity. London: MIT Press, 1994.

GIL, A. Métodos e técnicas de pesquisa social. São Paulo: Atlas, 2014.

GUILFORD, J. P. Creativity. American Psychologist, v. 5, n. 9, p. 444-454, 1950.

HARGREAVES, A. $\mathbf{O}$ ensino na sociedade do conhecimento: a educação na era da insegurança. Porto: Porto Editora, 2003.

HAIR, J. et al. Fundamentos de métodos de pesquisa em administração. São Paulo: Ed. Artmed, 2005.

JACKSON, N. et al. Developing creativity in higher education. London: Routledge, 2006.

JASKYTE, K.; TAYLOR, H.; SMARIGA, R. Student and faculty perceptions of innovative teaching. Creativity Research Journal, Mahwah, v. 21, n. 1, p. 1-6, 2009.

MALHOTRA, N. Pesquisa de Marketing: uma orientação aplicada. 4. ed. Porto Alegre: Bookman, 2001. 
MACKINNON, D. The creative person. Berkeley: University of California Press, 1963.

MOREIRA, A. Ambientes de Aprendizagem no Ensino de Ciência e Tecnologia. Belo Horizonte: CEFET-MG, 2007. (Notas de aula).

PARNES, S. J. Visionizing. East Aurora, N. Y.: D.O.K. Publishers, 1988.

PEARSON, Academia. Criatividade e inovação. São Paulo: Peb Pearson Nacional, 2011.

PIIRTO, J. Understanding those who create. Dayton, Ohio: Ohio Psychology Press, 1992.

PIMENTA, S.; ANASTASIOU, L. Docência no Ensino Superior. São Paulo: Cortez, 2002. (Coleção Docência em Formação)

PLUCKER, J.; BEGHETTO, R.; DOW, G. Why isn't creativity more important to educational psychologists? Potentials, pitfalls, and future directions in creativity research. Educational Psychologist, n. 39, p. 83-96, 2004.

PRENTKY, R. Creativity and psychopathology. In: GLOVER, J.; RONNING, R.; REYNOLDS, C. (Ed.). Handbook of Creativity. New York: Plenum Press, 1989.

RHODES, M. An analysis of creativity. The Phi Delta Kappan, v. 42, n. 7, p. 305-310, 1961.

ROTHENBERG, A. Creativity and madness: New findings and old stereotypes. London: The John Hopkins University Press, 1990.

RUNCO, M. Insight for creativity, expression for impact. Creativity Research Journal, v. 8, n. 4, p. 377-390, 1995.

SIMONTON, D. Creativity, leadership and chance. In: STERNBERG, R. (Ed.). The nature of creativity. Contemporary psychological perspectives. Cambridge, NY: Cambridge University Press, 1991. 
SOUZA, F. Criatividade e eficácia no ensino superior: percepções de estudantes e professores. Teoria, Investigação e Prática, Porto, v. 6, p. 189-213, 2001.

SOUZA, M.; ALENCAR, E. O curso de Pedagogia e condições para desenvolvimento da criatividade. Psicologia Escolar e Educacional, Campinas, v. 10, n. 1, p. 21-30, jan/jun. 2006.

STEIN, B. Memory and creativity. In: GLOVER, J.; RONNING, R.; REYNOLDS, C. (Ed.). Handbook of Creativity. New York: Plenum Press, 1989.

STERNBERG, R.; LUBART, T. Defying the crowd. London: The Free Press, 1995.

TERRA, J. 10 Dimensões da Gestão da Inovação - Uma Abordagem Para a Transformação Organizacional. Rio de Janeiro: Elsevier, 2012.

WEISBERG, R. Problem solving and creativity. In: STERNBERG, R. (Ed.). The nature of creativity. Contemporary psychological perspectives. Cambridge, NY: Cambridge University Press, 1991.

ZABALZA, M. O ensino universitário: seu cenário e seus protagonistas. Porto Alegre: Artmed, 2004. 